\title{
Incorporation of a physically based melt pond scheme into the sea ice component of a climate model
}

Article

Published Version

Flocco, D., Feltham, D. and Turner, A. K. (2010) Incorporation of a physically based melt pond scheme into the sea ice component of a climate model. Journal of Geophysical Research, 115. C08012. ISSN 0148-0227 doi: https://doi.org/10.1029/2009JC005568 Available at https://centaur.reading.ac.uk/30570/

It is advisable to refer to the publisher's version if you intend to cite from the work. See Guidance on citing.

Published version at: http://dx.doi.org/10.1029/2009JC005568

To link to this article DOI: http://dx.doi.org/10.1029/2009JC005568

Publisher: American Geophysical Union

All outputs in CentAUR are protected by Intellectual Property Rights law, including copyright law. Copyright and IPR is retained by the creators or other copyright holders. Terms and conditions for use of this material are defined in the End User Agreement.

www.reading.ac.uk/centaur 
Central Archive at the University of Reading

Reading's research outputs online 


\title{
Incorporation of a physically based melt pond scheme into the sea ice component of a climate model
}

\author{
Daniela Flocco, ${ }^{1}$ Daniel L. Feltham, ${ }^{1,2}$ and Adrian K. Turner ${ }^{1}$ \\ Received 12 June 2009; revised 12 February 2010; accepted 13 April 2010; published 10 August 2010.
}

[1] The extent and thickness of the Arctic sea ice cover has decreased dramatically in the past few decades with minima in sea ice extent in September 2005 and 2007. These minima have not been predicted in the IPCC AR4 report, suggesting that the sea ice component of climate models should more realistically represent the processes controlling the sea ice mass balance. One of the processes poorly represented in sea ice models is the formation and evolution of melt ponds. Melt ponds accumulate on the surface of sea ice from snow and sea ice melt and their presence reduces the albedo of the ice cover, leading to further melt. Toward the end of the melt season, melt ponds cover up to $50 \%$ of the sea ice surface. We have developed a melt pond evolution theory. Here, we have incorporated this melt pond theory into the Los Alamos CICE sea ice model, which has required us to include the refreezing of melt ponds. We present results showing that the presence, or otherwise, of a representation of melt ponds has a significant effect on the predicted sea ice thickness and extent. We also present a sensitivity study to uncertainty in the sea ice permeability, number of thickness categories in the model representation, meltwater redistribution scheme, and pond albedo. We conclude with a recommendation that our melt pond scheme is included in sea ice models, and the number of thickness categories should be increased and concentrated at lower thicknesses.

Citation: Flocco, D., D. L. Feltham, and A. K. Turner (2010), Incorporation of a physically based melt pond scheme into the sea ice component of a climate model, J. Geophys. Res., 115, C08012, doi:10.1029/2009JC005568.

\section{Introduction}

[2] The extent and thickness of the Arctic sea ice cover has decreased dramatically in the past few decades. Submarine data gathered from 1958 to 1976 indicates a decrease of sea ice thickness of about $1.5 \mathrm{~m}$ [Rothrock et al., 1999], and satellite observations show that the ice cover is continuing to thin [Laxon et al., 2003]. In September 2005 and 2007, historical minima of sea ice extent have been observed. These minima have not been predicted by even the most pessimistic model forecasts in the IPCC AR4 report [Solomon et al., 2007; Stroeve et al., 2007], and this, combined with the known shortcoming of model sea ice physics, suggests that the sea ice component of climate models should more realistically represent the physical processes controlling the sea ice mass balance. One of the physical processes poorly represented in sea ice models is the formation and evolution of melt ponds.

[3] Melt ponds accumulate on the surface of sea ice from snow and sea ice melt. A fraction of the surface melt runs directly into the sea off the edge of floes or through cracks, but the remainder forms melt ponds. The hydraulic head of a

\footnotetext{
${ }^{1}$ Centre for Polar Observation and Modelling, Department of Earth Sciences, University College London, London, UK.

${ }^{2}$ British Antarctic Survey, Cambridge, UK.

Copyright 2010 by the American Geophysical Union. 0148-0227/10/2009JC005568
}

melt pond, i.e., the height of the pond surface above sea level, drives meltwater to flush through permeable sea ice until the pond surface reaches sea level. Toward the end of the melt season melt ponds cover up to $50 \%$ of the sea ice surface. As fall progresses into winter, the ponds begin to freeze at their upper surface and the internal liquid region so formed slowly freezes, releasing latent heat. Melt ponds affect the heat and mass balance of the ice cover in various ways [Taylor and Feltham, 2004], for example the latent heat released in freezing of melt ponds keeps the ice relatively warm and reduces winter freezing. However, the most important effect that melt ponds have on the heat and mass balance of the ice cover is through their impact on the albedo of the ice which they cover.

[4] Pond-covered ice absorbs more solar radiation, and therefore melts more quickly, than the bare sea ice, with the melt rate beneath melt ponds estimated to be up to 2-3 times greater than that of bare ice [Fetterer and Untersteiner, 1998a]. The spectrally averaged, shortwave albedo of pondcovered ice has been measured in field experiments to be between 0.1 and 0.5 [e.g., Grenfell and Maykut, 1977; Perovich et al., 2002; Eicken et al., 2004], and is principally determined by the optical properties and physical depth of the ice beneath the pond, both of which have some correlation with pond depth. These albedo values are much lower than those of bare ice and snow covered ice, which are in the range 0.52 to 0.87 [Perovich, 1996]. The reason that pond-covered ice has a lower albedo than bare ice is that a drained, highly 
scattering granular layer (known as the surface scattering layer) forms at the surface of bare ice and the presence of meltwater prevents this surface scattering layer from forming [Light et al., 2008]. The pond itself absorbs a relatively small amount of radiation (a few percent, dependent upon thickness) and scatters almost none, and pond-covered ice absorbs considerably less radiation than bare ice of the same thickness. The transmittance of solar radiation through pondcovered ice into the ocean is estimated from field observations to be 3-5 times greater than that through bare ice of similar thickness [Perovich, 2005], although this is dependent upon the thickness of the ice and pond. Light et al. [2008], combining laboratory observations and a radiative transfer model, estimate that a $0.4 \mathrm{~m}$ pond underlain with $1 \mathrm{~m}$ of ice will transmit nearly $50 \%$ of the incident solar, shortwave radiation to the ocean below whereas a $0.4 \mathrm{~m}$ pond on $3 \mathrm{~m}$ thick ice transmits about $15 \%$ of the solar radiation to the ocean below. Based upon these, and numerous other, observations, many have referred to pond-covered ice as "windows" that let light into the ocean below the ice.

[5] The fractional area of the sea ice surface covered in ponds is needed to determine the area-averaged albedo of the ice cover, an important quantity in the sea ice components of Global Climate Models (GCMs). The fractional area covered in ponds has been most extensively studied from visual photography using air craft and balloons [Derksen et al., 1997; Tschudi et al., 2001; Perovich and Tucker, 1997; Eicken et al., 2004], but also from satellite imagery [Barber and Yackel, 1999; Fetterer and Untersteiner, 1998b]. The evolution of the melt pond cover on a given region of sea ice, such as a particular floe, is typically highly variable since it is controlled by a number of competing factors. Based upon observations, Eicken et al. [2002] divided the evolution of the melt pond cover into four main stages. The first stage is when snowmelts to produce the initial source of meltwater; at this time the ice is relatively impermeable and lateral meltwater transport to local topographic lows in ice height or cracks in the ice cover determines the initial pond cover. On rougher ice, this is typically the stage of maximum pond coverage. On particularly flat, typically first-year, ice it is possible for snowmelt to flood the surface so that the pond fraction may cover up to $60 \%$ of the surface, Eicken et al. [2004]. The second stage is characterized by the completion of snowmelt so that meltwater is now generated from sea ice melt only and the increase in permeability of the ice cover. Ponds can now only remain above sea level if the ice melt supply from the catchment area surrounding a given pond exceeds the drainage rate, which is rare, and the pond covered fraction of the ice cover diminishes as the ponds drain to sea level. In the third stage, vertical drainage is sufficiently rapid that all ponds are at sea level, however since this is also the period in which melting is most rapid, the pond area fraction increases. Some ponds will melt through completely to the ocean. On flatter, first year ice this can be a period of maximum pond coverage. On rougher ice, the pond area fraction tends to be lower, and certainly individual ponds are of smaller area, since topography limits lateral meltwater transport [Fetterer and Untersteiner, 1998a]. The final stage is when the ponds freeze over at their upper surface.

[6] Various attempts have been made to model melt ponds. Taylor and Feltham [2004] developed a one-dimensional model of melt ponds that consisted of heat and salt balance equations, a two stream radiation model, and treated the sea ice as a mushy layer [Feltham et al., 2006]. This model was forced with SHEBA data [Perovich et al., 1999] and was able to produce realistic pond depth and albedo evolution. A subsequent model was developed to study the area evolution of melt ponds on sea ice [Lüthje et al., 2006]. This model divides a sea ice floe into square cells, inside which the pond height and ice depth are recorded and allowed to evolve according to the state of the surrounding cells (the model thus forms a cellular automaton). While these two models have led to some improvements in our understanding of the processes governing melt pond evolution, they are not suitable for inclusion into a GCM. It is for this reason that we developed a melt pond model for use in the sea ice component of a GCM [Flocco and Feltham, 2007].

[7] In the work of Flocco and Feltham [2007], we presented the theory behind our melt pond model and ran the model in stand-alone mode, which means that the model was set up to simulate the melt pond cover with the melting rates of snow, bare ice, and pond-covered ice imposed (i.e., no heat transfer calculations were performed), in a similar way to the model of Lüthje et al. [2006]. Since then, we have incorporated the melt pond theory into the Los Alamos CICE sea ice model, which performs, among other things, the heat transfer calculations. Incorporation of the melt pond theory into CICE has required extension of the original theory to deal with the refreezing of melt ponds. This work, together with some other minor modifications, is described in this paper.

[8] The model presented here includes snowmelt, reduced albedo of pond-covered ice, vertical drainage, and freezing of ponds and thus can capture many of the observed features of the pond evolution summarized above. However, since the model does not represent the actual topography of the ice cover, which is a necessary limitation of the need to be able to incorporate the model into the current generation of GCM sea ice components, it can only represent lateral meltwater transport in a crude manner. Lateral meltwater transport in this model [Flocco and Feltham, 2007] is accounted for by invoking the continuum hypothesis, upon which all GCMstyle sea ice models are based: it is assumed that a given point on an ice cover is surrounded by ice of all surface heights. A necessary consequence of this assumption is that meltwater is transported to the ice of lowest surface height. It is observed that meltwater will travel many hundreds of meters to reach a local topographic low, e.g., Eicken et al. [2002]. It is assumed in the model used in this paper that meltwater is transported to the lowest surface height within one time step of the model. While one can clearly imagine situations in which this is unrealistic, without a representation of surface topography the distance to points of lowest surface height, and thus the time required to reach these locations, cannot be estimated. Observations and model simulations (F. Scott and D. L. Feltham, A model of the three-dimensional evolution of Arctic melt ponds on Firstyear and Multi-year sea ice, submitted to Journal of Geophysical Research, 2010) suggest that this model assumption does not strongly affect the predicted pond cover, which is most likely due to the fact [e.g., Perovich et al., 2003; Eicken et al., 2004] that for the majority of the melt season the ponds are observed to be at sea level, and this is faithfully represented in the model [Flocco and Feltham, 2007]. 


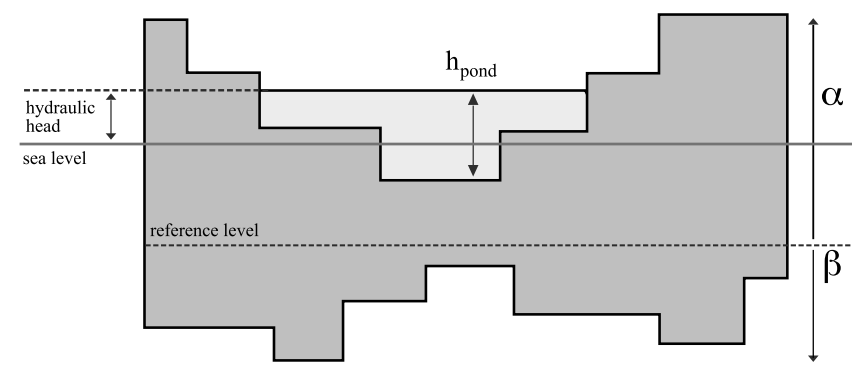

Figure 1. Schematic of sea ice thickness distribution reorganized as an ice floe. Here $\alpha$ and $\beta$ are the top and the bottom part of the sea ice thickness distribution and $h_{\text {pond }}$ is the pond depth.

[9] We have conducted a number of numerical simulations using the sea ice model with our model of melt ponds in order to demonstrate the impact that the melt ponds have on the sea ice mass balance and to examine sensitivity of the simulations to aspects of the melt pond model. While the incorporation of our melt pond routine significantly alters the mass balance of the ice cover, the resulting simulations are not unreasonable and do not cause any substantial redistribution of sea ice. It is not the purpose of this paper to accurately simulate the sea ice cover, since this would require calibration against observations and tuning of uncertain parameters not related to melt ponds, and would detract from our main aim, which is the investigation of the impact of melt ponds on the sea ice mass balance.

[10] In section 2, we describe essential elements of our previous melt pond theory and the CICE sea ice model, including a semi-empirical pond parameterization included in the standard CICE release version 4.1, and briefly describe how the output of the melt pond model is used to calculate albedo. In section 3, we describe how our model deals with the refreezing of melt ponds and our treatment of the permeability of sea ice. In section 4 , we first present simulations of the sea ice cover with, and without, melt ponds and then examine the sensitivity of the simulations using our melt pond model to variations in the sea ice permeability, the number of thickness categories resolved in CICE, and the meltwater redistribution scheme. We discuss our results in section 5 and summarize our main conclusions in section 6 .

\section{Scientific Context}

\subsection{Elements of the Melt Pond Theory of Flocco and Feltham [2007]}

[11] Almost all sea ice models characterize the sea ice cover with one state variable, namely ice thickness. Moreover, since a single model grid cell would in reality contain ice of various thicknesses, the more sophisticated sea ice models characterize the ice cover with a thickness distribution function [Thorndike et al., 1975]. The thickness distribution function $g(h, \boldsymbol{x}, t)$ is defined such that $g d h$ is the fractional area of ocean covered by ice whose thickness lies between $h$ and $h+d h$ at (horizontal) position $\boldsymbol{x}$ and time $t$. This distribution function is normalized so that

$$
\int_{0}^{\infty} g d h=1 .
$$

[12] In practice, the distribution function is discretized, e.g., in the standard implementation of CICE version 4.1, there are 5 thickness categories. When meltwater forms, it runs downhill under the influence of gravity and thus the topography of the ice cover plays a crucial role in determining the melt pond cover. While the thickness distribution function describes the relative areas within a grid cell covered in ice of a certain thickness, the spatial disposition of this ice, i.e., the topography of the ice cover, is not captured. In order to redistribute meltwater over the ice surface, necessary to calculate pond area and depth, we [Flocco and Feltham, 2007] split the sea ice thickness distribution function into a surface height distribution function $\alpha(h, \boldsymbol{x}, t)$ and a basal depth distribution function $\beta(h, \boldsymbol{x}, t)$ (see Figure 1). The procedure for determining $\alpha(h, \boldsymbol{x}, t)$ and $\beta(h, \boldsymbol{x}, t)$ from $g(h, \boldsymbol{x}, t)$ is described in detail by Flocco and Feltham [2007]. Briefly, we consider each thickness category to be separately in hydrostatic equilibrium and the position of sea level is calculated assuming that the ice in the whole grid cell is rigid and in hydrostatic equilibrium; the fraction of the ice above a reference height forms $\alpha(h, \boldsymbol{x}, t)$ and the fraction below the reference height forms $\beta(h, \boldsymbol{x}, t)$. The principle for meltwater distribution within a given grid cell and time step is, then, to take the volume of meltwater (suitably modified by advection, precipitation, melting, freezing, drainage and run-off) and cover the ice thickness categories in order of increasing surface height (accounting for saturated snow, where present).

[13] In the standalone melt pond model [Flocco and Feltham, 2007], we discretized the thickness, surface height, and basal depth distribution functions with 80 ice thickness categories. A layer of snow of variable depth was initially placed on the ice, and the melting rates for the snow, the bare sea ice, pond-covered ice, and ice-ocean interface were prescribed. As ice in a given surface height or basal depth category melts/freezes, it is transferred into a lower/higher height or depth category. The model does not account for lateral melt of the ponds. It is observed that the greatest determinant of the pond fraction is the area of ice below sea level, e.g., Perovich et al. [2003] and Eicken et al. [2002, 2004]. Lateral melt plays a relatively minor role in determining the pond area since it alters the area of low-lying ice to a relatively small degree and the lack of topography in continuum GCM-style models limits the realism with which lateral melting could be modeled. The most straightforward approach to incorporating lateral melt would be to cause volume transfer between thickness classes, which is algorithmically equivalent to the effect of vertical, surface melt, although some assumptions would be required regarding total pond perimeter.

[14] The Flocco and Feltham [2007] model simulations produced realistic results, with a maximum pond covered area of about $50 \%$ of the sea ice surface, in agreement with field observations. Various sensitivity studies were performed (varying, for example, mean snow and ice thickness). In particular, it was found that by using an ice thickness distribution that reproduces young, flatter ice, the pond area increases and the maximum pond depth decreases, while pond area decreases and the pond depth increases when using a sea ice thickness distribution that simulates old, rougher ice. In particular, and most relevant to application within the current generation of GCMs, it was found that a 
drastic reduction of the number of ice thickness categories still yielded realistic results in terms of pond area and depth.

\subsection{Elements of the Los Alamos Sea Ice Model CICE}

[15] The Los Alamos sea ice model CICE is a dynamicthermodynamic sea ice model designed for inclusion within a GCM. In its standard configuration, CICE includes 5 ice thickness categories. The sea ice velocity is calculated from a momentum balance equation that accounts for air drag, ocean drag, Coriolis force, sea surface tilt, and the (divergence of) internal ice stress. The internal ice stress is calculated using the viscous plastic rheology of Hibler [1979], with artificial elasticity included to aid the solution procedure [Hunke and Dukowicz, 1997]. The redistribution of ice thickness in ridging follows the work of Rothrock [1975]. For further details, see Lipscomb et al. [2007].

[16] The CICE model solves one-dimensional, vertical heat balance equations for each thickness category and snow, if it is present. The sea ice heat balance equation is nonlinear to account for brine content within the sea ice, and contains a source term to account for absorbed solar radiation, and is based on the model of Maykut and Untersteiner [1971] using the energy conserving scheme of Bitz and Lipscomb [1999]. The upper sea ice boundary condition consists of a balance of shortwave, longwave, sensible, latent, and conductive heat fluxes when the ice surface is below freezing. When the surface temperature warms to the melting temperature, it is held at the melting temperature and the flux imbalance drives melting through a moving boundary (Stefan) condition. No surface freezing is possible. The lower sea ice boundary conditions are that the ice temperature is equal to the ocean mixed layer temperature, and a Stefan condition [Carslaw and Jaeger, 1997] determining either melting or freezing dependent on the difference between the conductive heat flux in the ice toward the atmosphere and the turbulent oceanic heat flux into the ice.

\subsection{Calculation of Surface Albedo}

[17] The main outputs of the melt pond model of Flocco and Feltham [2007], and the modified model presented in this paper, are the pond area and pond depth. These outputs are then used in a separate routine within CICE to calculate the area-averaged sea ice albedo. The standard version of CICE version 4.1 also contains a semi-empirical parameterization for determining melt pond area and depth based upon the volume of meltwater $V$ present in a grid cell. This parameterization thus generates the same outputs as does our melt pond theory. This parameterization was devised to improve the match between CICE simulations and SHEBA observations, and is unpublished (D. Bailey, personal communication, 2009).

[18] In the CICE semi-empirical scheme, pond area $a_{\text {pond }}$ and depth $h_{\text {pond }}$ are calculated according to

$$
\begin{aligned}
& a_{\text {pond }}=\sqrt{1.25 V} \\
& h_{\text {pond }}=0.8 a_{\text {pond }} .
\end{aligned}
$$

If the air temperature is below freezing, the meltwater volume at time step $t+1$ is decreased from that at time step $t$ according to

$$
V_{t+1}=V_{t} \exp \left(0.1 \frac{d T_{s}-2}{T_{\text {imelt }}-2}\right)
$$

where $d T_{s}$ is the difference between the ice melting temperature $T_{\text {imelt }}$ (set equal to $0^{\circ} \mathrm{C}$ ) and the surface temperature.

[19] In the simulations presented in sections 4 and 5, we used either the output of our melt pond model or the CICE semi-empirical parameterization as input to the Community Climate System Model (CCSM) version 3 albedo scheme. The CCSM albedo scheme determines surface albedo from spectral band (visible or near infrared), presence of snow, presence and depth of melt ponds, and sea ice thickness. The direct and diffuse albedos are considered equal (the solar zenith is ignored) but this does not constitute a major error since melt ponds form at a time of the year when the difference between diffuse and direct albedo is rather small. The albedo of the pond-covered ice is calculated taking into account the pond area, the pond albedo, and the bare ice albedo. The pond albedo decreases exponentially with pond depth following the Ebert and Curry parameterization [1993], with the minimum allowable value being the ocean albedo. For further details on the CCSM albedo scheme see Ebert and Curry [1993] and Grenfell and Maykut [1977].

\section{New Development of the Melt Pond Model of Flocco and Feltham [2007]}

\subsection{Refreezing of Ponds}

[20] In our previous work, we studied the evolution of melt ponds only during the melt season. However, toward the end of the melt season air temperatures begin to drop and melt ponds freeze over at their upper surface to form ice lids, with meltwater between the ice lid and pond bottom. Here, we extend our previous theory to allow the ponds to freeze over. When the ice lids first form, diurnal variation in surface heat fluxes can cause the lid to form and melt again but after a short transition period the ice lids persist and grow downward until the meltwater is completely frozen.

[21] When the surface energy budget of a melt pond becomes negative, the pond will cool down. Taylor and Feltham [2004], in their one-dimensional simulation of melt ponds, showed that the ponds are turbulently convecting so that so that the pond temperature is close to uniform, except for narrow diffusive boundary layers at the top and bottom. The turbulent heat transfer is efficient and is modeled using the four-thirds law for turbulent convection. (The four-thirds law arises when the heat flux across a fluid layer is assumed to be independent of the depth of a fluid layer, so that the Nusselt number, which is the ratio of the convective to diffusive heat flux, is proportional to the Rayleigh number to the power of one third [Linden, 2000; Taylor and Feltham, 2004].) It is easy to show [e.g., Taylor and Feltham, 2004] that ponds of all reasonable depths (up to 2-3 m) will cool down to close to the freezing temperature within a few time steps of the CICE model (each time step is $1 \mathrm{~h}$ ) when the net surface energy budget is negative. 
Table 1. Minimum and Maximum Values of the Sea Ice Thickness, the Sea Ice Concentration, the Fractional Melt Pond Covered Area, and the Melt Pond Depth for the CPOM, CICE, and "No Pond" Model Runs ${ }^{\mathrm{a}}$

\begin{tabular}{|c|c|c|c|c|c|c|c|c|}
\hline & \multicolumn{2}{|c|}{$\mathrm{Hi}(\mathrm{m})$} & \multicolumn{2}{|c|}{ Aice $(\%)$} & \multicolumn{2}{|c|}{ Apond $(\%)$} & \multicolumn{2}{|c|}{ Hpond (m) } \\
\hline & Min & $\operatorname{Max}$ & Min & Max & Min & Max & Min & $\operatorname{Max}$ \\
\hline & & 1.9 & 0 & 0. & 0 & & 0.0 & 0.60 \\
\hline & & 1.8 & 20 & 0.9 & 0 & & 0.0 & 0.22 \\
\hline No pond & 2.20 & 3.11 & 0.62 & 0.99 & N/A & N/A & N/A & $\mathrm{N} / \mathrm{A}$ \\
\hline
\end{tabular}

${ }^{\mathrm{a}} \mathrm{Hi}$, sea ice thickness; Aice, sea ice concentration; apond, fractional melt pond covered area; hpond, melt pond depth.

[22] When the pond temperature reaches its freezing point, a layer of ice is formed at its upper surface. The rate of growth of the ice lid $\left(H_{u i}\right)$ is given by the Stefan energy budget at the lid-pond interface

$$
\rho_{i} L \frac{d H_{u i}}{d t}=k_{i} \frac{\partial T_{i c e}}{\partial z}-k_{p} \frac{\partial T_{\text {pond }}}{\partial z},
$$

where $\rho_{i}$ is the ice density, $L$ is the latent heat of fusion of pure ice per unit volume, $T$ is the temperature, $t$ is time, $z$ is vertical position and $k_{i}$ and $k_{p}$ are the thermal conductivity of the ice lid and pond respectively. The second term on the right hand-side is close to zero since the pond is almost uniformly at the freezing temperature. Approximating the temperature gradient in the ice lid as linear, $k_{i} \frac{\partial T_{i c e}}{\partial z} \approx k_{i} \frac{\Delta T_{i c e}}{H_{i i}}$, the Stefan condition yields the classic Stefan solution for ice lid depth $H_{u i}=\sqrt{\frac{2 k_{i}}{\rho_{s} L} \Delta T_{i c e}} t^{1 / 2}$. The volume (thickness) of the ice lid is stored as a variable and used in the following time steps. The routine checks the surface flux conditions in the next time step and allows the ice-lid to grow, partially melt, or melt completely as appropriate. The volume of the ice lid is subtracted from the pond volume and added to the ice floe volume, contributing to the evolution of the ice thickness distribution. Calculations show that a floating ice layer of thickness $70 \mathrm{~cm}$ can form in two months, which is confirmed by observations of under-ice ponds a few months after the initial surface freezing [Perovich et al., 2002].

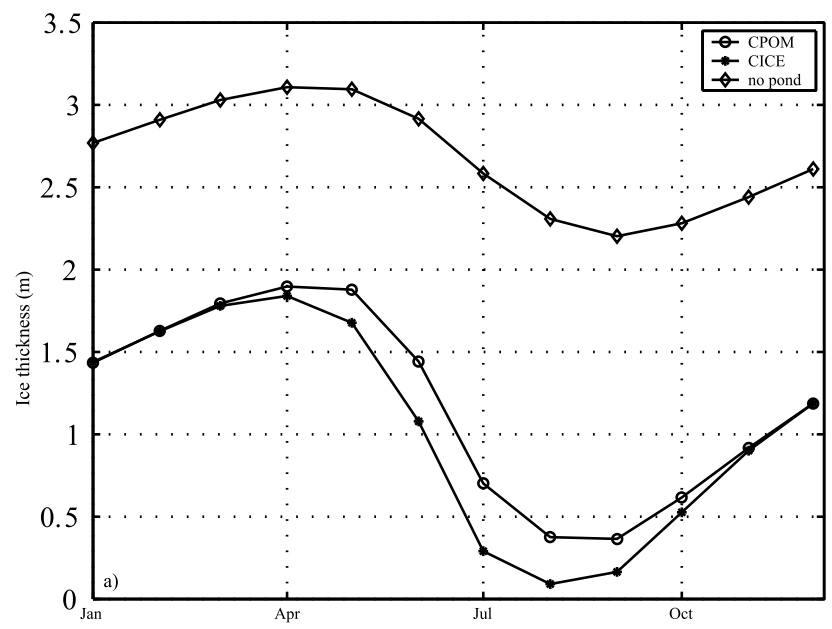

\subsection{Permeability of the Sea Ice}

[23] As meltwater accumulates on the ice cover, a prescribed fraction (we chose $20 \%$ based on sensitivity studies of Flocco and Feltham [2007]) runs off the edges of the floes or through cracks. The remaining meltwater sits on the ice surface and may drain vertically through the ice and into the ocean while the hydraulic head is positive (the pond surface is above sea level). The location of sea level with respect to the ice surface is calculated at each time step from a hydrostatic balance. The vertical drainage of meltwater through the sea ice and into the ocean is calculated using Darcy's Law for flow through a permeable medium.

[24] In our previous work [Flocco and Feltham, 2007], for simplicity, the permeability was chosen to be a prescribed function of time (based upon measurements of Eicken et al. [2004]): relatively impermeable in the early part of the melt season, increasing in permeability during the main season, and decreasing toward the end of the melt season. Although convenient for the previous work, we wish to be able calculate permeability according to the physical state of the ice. During the melting season sea ice warms so that the brine pathways enlarge and multiply so that the solid volume fraction $\varphi$ decreases and the sea ice becomes more permeable. Here, we adopt the relationship between the vertical permeability of sea ice $\Pi\left(\mathrm{m}^{2}\right)$ and solid fraction of sea ice proposed by Golden et al. [2007],

$$
\Pi=3\left(1-\phi^{3}\right) \times 10^{-8} .
$$

Since the solid fraction varies throughout the depth of the sea ice, so does the permeability. The rate of vertical drainage is determined by the lowest (least permeable) layer, corresponding to the highest solid fraction. From the equations describing sea ice as a mushy layer [Feltham et al., 2006], the solid fraction is determined by

$$
\phi=\frac{c_{b u l k}-C(T)}{C_{i}-C(T)},
$$

where $c_{\text {bulk }}$ is the bulk salinity of the ice (3.2 parts per thousand in this work), $C(T)$ is the concentration of salt in the brine and $C_{i}$ is the concentration of salt in the ice crystals (zero

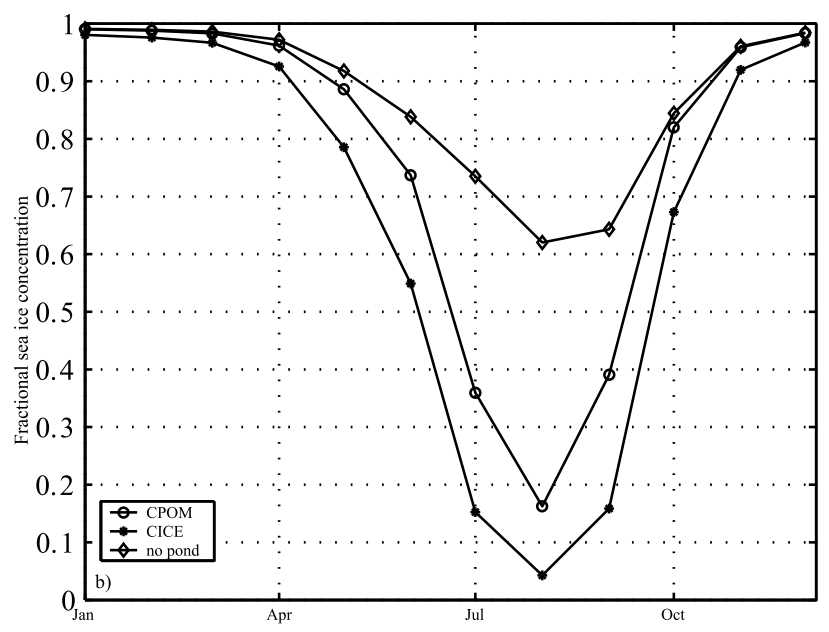

Figure 2. (a) Climatology of the model-domain average of sea ice thickness for the CPOM, the CICE and the "no pond" model runs. (b) Climatology of the model-domain average of sea ice concentration for the CPOM, the CICE, and the "no pond" model runs. 

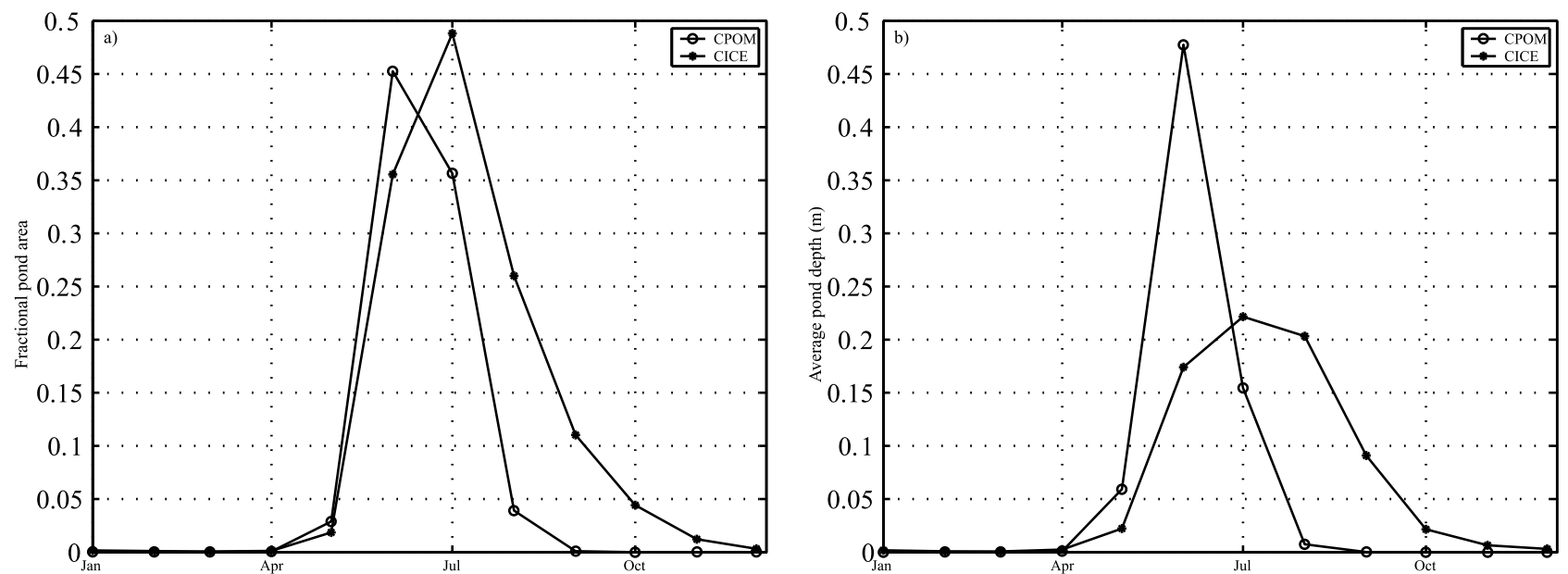

Figure 3. (a) Climatology of the model-domain average of fractional pond area for the CPOM and the CICE model runs. (b) Climatology of the model-domain average of melt pond depth for the CPOM and the CICE model runs.

here). The function $C(T)$ gives the liquidus concentration of brine at which ice and brine can coexist in thermodynamic equilibrium, and is the one presented by Assur [1958] $C(T)=$ $-1.20-21.8 T-0.919 T^{2}-0.0178 T^{3}$. In practice, once the ice become permeable enough, around $10^{-10} \mathrm{~m}^{2}$, the pond quickly drains to sea level and stays at that level.

\section{Results}

[25] We present results using a standalone version of CICE version 4.1, modified to include our melt pond scheme, with atmospheric and oceanic forcing. We use the standard parameter choices within CICE version 4.1 and have not tuned the model against observations. The simulations we present are designed to explore the role that melt ponds play in determining the mass balance of sea ice and not for detailed comparison against observations.

[26] A regional domain consisting of the Arctic basin and peripheral seas is used with open boundaries at the Bering Strait and in the mid Greenland, Iceland and Norwegian seas. Baffin Bay is filled in so there is no open passage through the Canadian Archipelago to the North Atlantic. The grid is based on the ORCA1 tripolar grid developed for the NEMO ocean code [Madec, 2008].
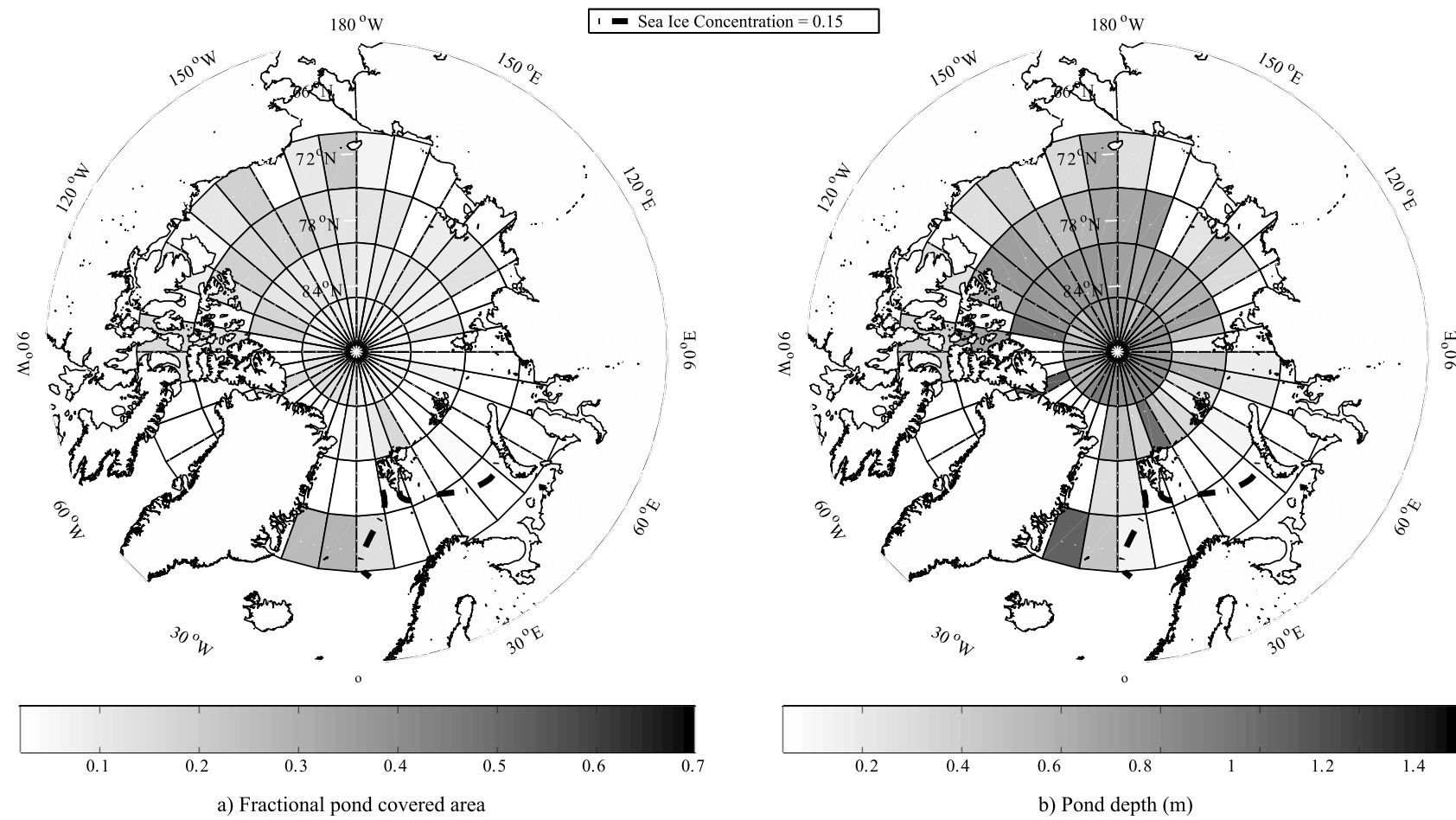

Figure 4. (a) Average (1980-2001) fractional pond area for July using the CPOM scheme. (b) Average (1980-2001) pond depth for July using the CPOM scheme. 

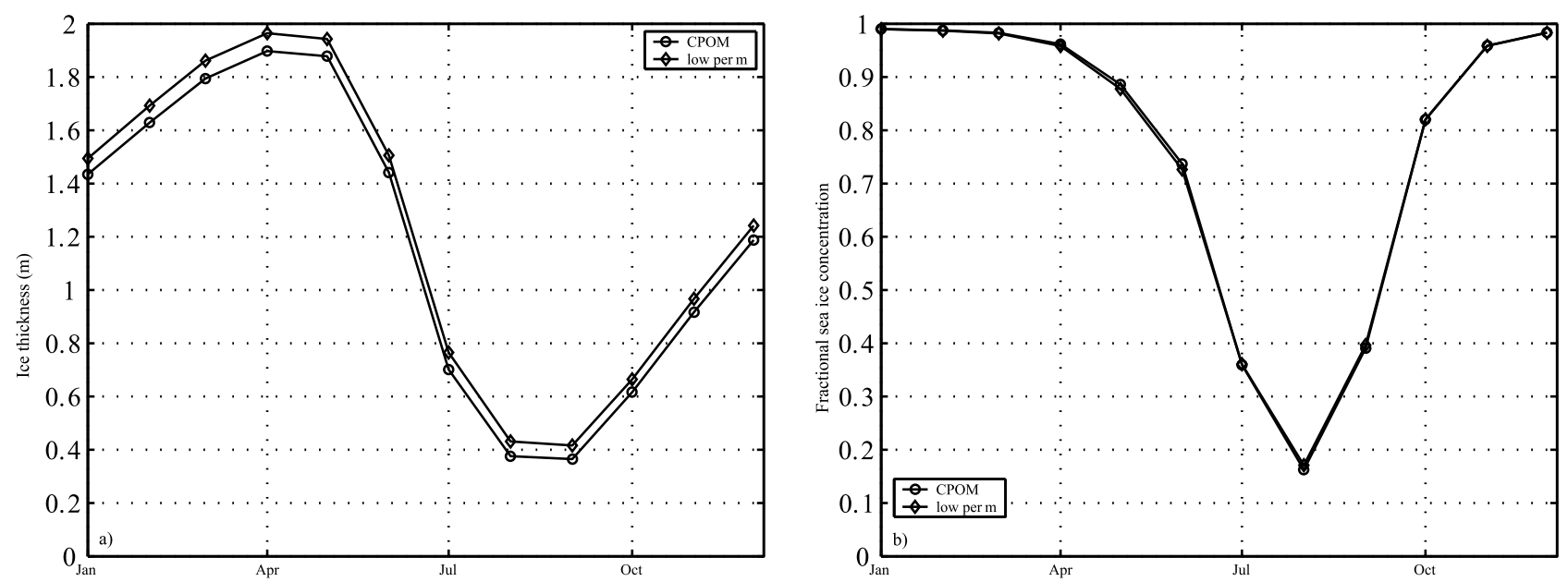

Figure 5. (a) Climatology of the model-domain average of sea ice thickness for the CPOM and the low permeability model runs. (b) Climatology of the model-domain average of sea ice concentration for the $\mathrm{CPOM}$ and the low permeability model runs.

[27] The atmospheric forcing closely follows that of Miller et al. [2006]. ECMWF re-analysis ERA-40 data is used for $10 \mathrm{~m}$ wind speeds, long and shortwave downwelling radiation, and snowfall. A forcing period of six hours is used for the wind speed and daily forcing for the radiation and snowfall. The POLES Sea Ice Model Forcing Data Set [Zhang et al., 1998] is used for daily two meter air temperatures and humidities. ERA-40 data is not used for these forcing variables because the ERA-40 air temperature is known to frequently exceed the freezing point during the summer over Arctic sea ice [Flato and Hibler, 1995]. The CICE model contains a representation of the oceanic mixed layer and the heat flux at the ice-ocean interface depends on the mixed layer temperature and is calculated using a turbulent heat transfer equation.

[28] The initial sea surface temperature and salinity is set from the Polar science center Hydrographic Climatology (PHC) [Steele et al., 2001]. The model is spun-up for twelve years using repeated 1980 forcing data, after which it is run from 1980 to 2001, the period from which scientific results are taken. We produce a climatology over the period 1980 2001 for monthly means of ice thickness, ice concentration, pond area and albedo, averaged over the model domain.

[29] In section 4.1 we describe the results obtained with no pond parameterization, with the semi-empirical melt pond parameterization (hereafter, the CICE pond scheme), and with our new pond scheme (hereafter, the CPOM pond scheme). In section 4.2 we explore the sensitivity of the simulations with the CPOM pond scheme to variation in ice permeability, the number of thickness categories, and the meltwater redistribution scheme, which are the factors that have most impact on the CPOM melt pond distribution.

\subsection{Sea Ice Simulations With and Without Melt Ponds}

[30] Table 1 summarizes the main results from our simulations in this section. In Figure 2, we show the sea-
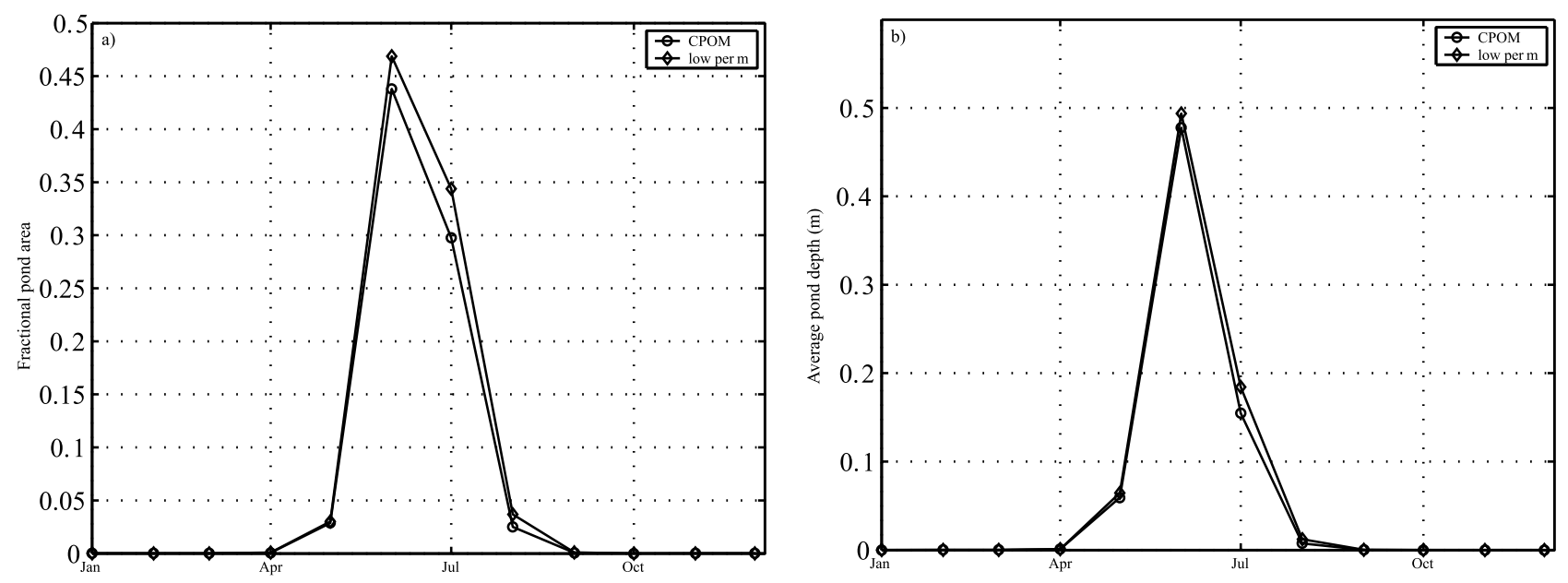

Figure 6. (a) Climatology of the model-domain average of fractional pond area for the CPOM and the low permeability model runs. (b) Climatology of the model-domain average of melt pond depth for the CPOM and the low permeability model runs. 

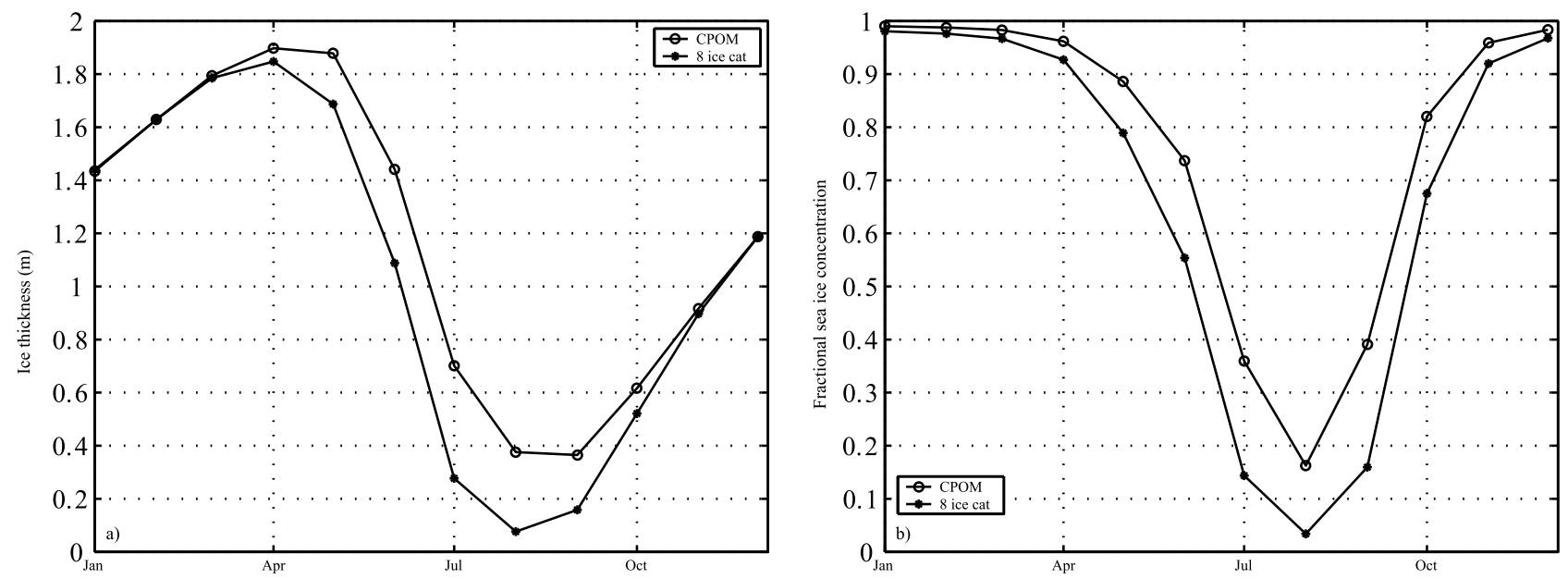

Figure 7. (a) Climatology of the model-domain average of sea ice thickness for the CPOM and the eight ice categories model runs. (b) Climatology of the model-domain average of sea ice concentration for the $\mathrm{CPOM}$ and the eight ice categories model runs.

sonal cycle of basin-averaged sea ice thickness and sea ice concentration with no ponds (labeled "no pond"), with the CICE pond scheme (labeled "CICE") and with the CPOM pond scheme (labeled "CPOM"). From Figure 2a, it is evident that the presence of melt ponds has a significant impact on the ice thickness and the seasonal variation in ice thickness is greater when melt ponds are included. The sea ice concentration, and its seasonal variability, is also strongly affected by the presence of melt ponds (Figure $2 b$ ), as is to be expected since melt ponds can cause thin ice to melt through completely, reducing the ice concentration.

[31] We note that the CICE pond scheme simulation shows the seasonal ice retreating earlier, in between March and April, than the CPOM and no melt pond simulations. The CICE pond scheme simulations also show lower ice thickness and ice concentration than the CPOM scheme.

[32] In Figure 3, we show the seasonal cycle of basinaveraged pond covered area fraction and pond depth for the CICE and CPOM pond schemes. Both schemes produce pond area fractions (Figure 3a) comparable with the literature
[Perovich et al., 2002] but differ in behavior at the beginning of the refreezing season. The CPOM scheme shows a rapid decrease in the pond area at the end of the melting season. This is due to the explicit parameterization of the refreezing process. The pond area obtained from the CICE scheme shows a slow decrease in pond area fraction, with ponds still present in November (not observed in reality).

[33] Figure 3b shows that the pond depth in the CICE pond scheme produces a lower maximum pond depth value than the CPOM scheme but the CICE pond depth decays rather slowly to zero in November. The CPOM pond scheme produces a greater maximum pond depth, but the pond depth decays more rapidly as the ponds freeze over. The pond depth presented for the CPOM pond scheme is for the ponds exposed to the air only. An under-ice pond will still have a positive pond depth that will slowly freeze in the way described in section 3.1. The average July (1980-2001) maps of fractional pond-covered area and depth using the CPOM melt pond scheme are shown in Figure 4.
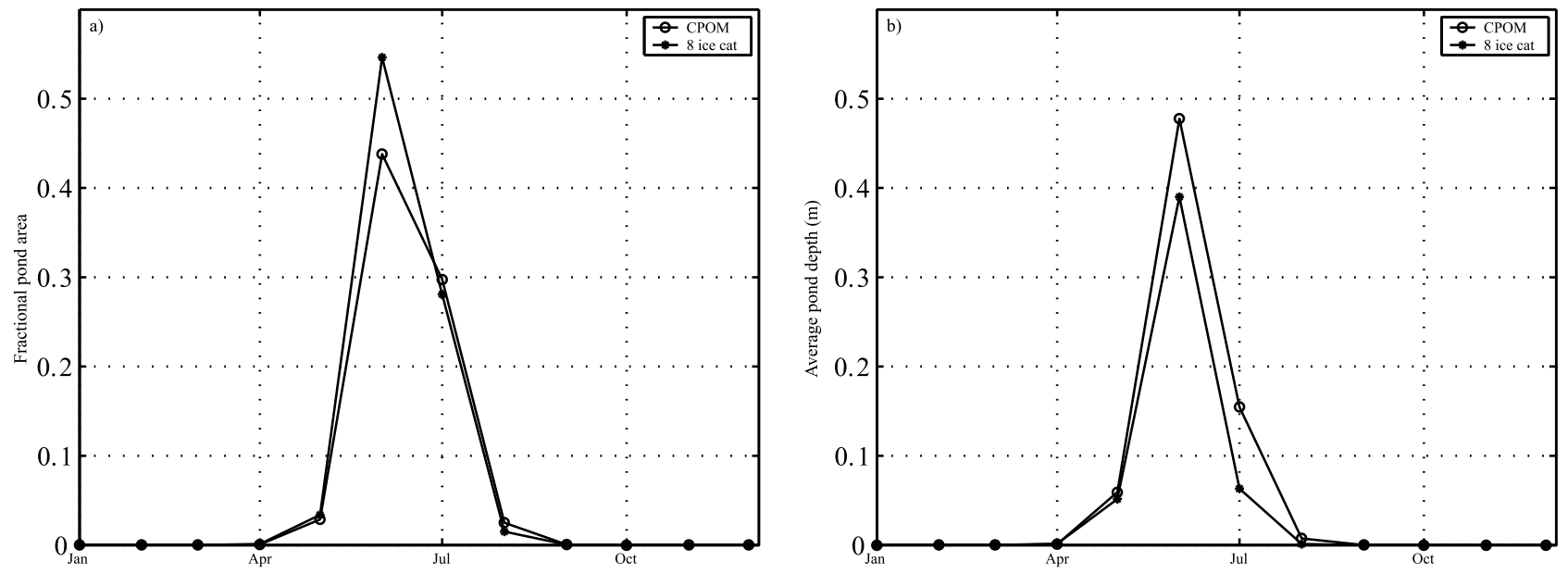

Figure 8. (a) Climatology of the model-domain average of fractional pond area for the CPOM and the eight ice categories model runs. (b) Climatology of the model-domain average of melt pond depth for the CPOM and the eight ice categories model runs. 
Table 2. Intervals of the Sea Ice Thickness Used in the Model Runs When Using Eight or Five Ice Categories

\begin{tabular}{cc}
\hline $\begin{array}{c}\text { Eight Ice Categories } \\
\text { Ice Thickness }(\mathrm{m})\end{array}$ & $\begin{array}{c}\text { Five Ice Categories } \\
\text { Ice Thickness }(\mathrm{m})\end{array}$ \\
\hline $0-0.375$ & $0-0.60$ \\
$0.375-0.875$ & $0.60-1.40$ \\
$0.875-1.500$ & $1.40-2.40$ \\
$1.500-2.250$ & $2.40-3.60$ \\
$2.250-3.125$ & $3.60-5.00$ \\
$3.125-4.125$ & \\
$4.125-5.250$ & \\
$5.250-6.500$ & \\
\hline
\end{tabular}

\subsection{Sensitivity of Melt Pond Scheme to Model Parameters}

\subsubsection{Variation of Permeability}

[34] In Figure 5, we show the seasonal cycle of basinaveraged ice thickness and ice concentration with the standard CPOM run of the previous section and an equivalent run using a sea ice permeability that is artificially reduced by a factor of $10^{5}$. The effect of the reduction in permeability is to increase the ice thickness by about $0.2 \mathrm{~m}$, but little impact is found on the ice concentration. The increase in ice thickness occurs because meltwater with a positive hydraulic head (i.e., the pond surface is above sea level) is trapped on the ice floe because vertical drainage is so weak, and the standing meltwater freezes over in winter and contributes to the ice thickness.

[35] In Figure 6, we show the seasonal cycle of basinaveraged pond covered area fraction and pond depth with the standard CPOM run of the previous section and an equivalent run using the low sea ice permeability. The low permeability run has an increase in pond area of about $10 \%$ but the pond depth is similar in the two cases; this means that the extra volume of meltwater in the low permeability case is used to cover a greater fraction of the low ice thickness categories. We performed similar calculations in which the sea ice permeability was artificially increased by a factor of $10^{3}$. These runs (not shown) were almost identical to the standard CPOM run, indicating that in the standard run the ponds quickly drain to sea level and remain there.

\subsubsection{Variation of Number of Ice Categories}

[36] Our melt pond routine places meltwater on the lowest ice first and then, once this is filled up to the height of the next lowest ice, meltwater is placed on the next lowest ice, and so on. Because of this, the melt pond characteristics are sensitive to where we place the limits of the ice thickness categories. In Figure 7 we show the seasonal cycle of basinaveraged ice thickness and ice concentration and in Figure 8 we show the seasonal cycle of basin-averaged pond covered area fraction and pond depth with the standard CPOM run of the previous section and an equivalent run in which the number of ice thickness categories is increased to eight ice thickness categories from five in the standard case. The thickness categories we used are given in Table 2.

[37] We see from Figure 7 that the run with the increased number of ice thickness categories produces ice that is up to $0.35 \mathrm{~m}$ thinner, and a decrease of up to $10 \%$ in ice concentration, compared to the standard CPOM run during the melt season. The reason for this, as can be seen in Figure 8, is that the run with the larger number of thickness categories produces ponds that cover up to $10 \%$ more of the sea ice surface. Since a greater fraction of the ice surface is covered in meltwater in the run with eight thickness categories, melting is enhanced over a larger area. Although the ponds cover a larger area in the eight thickness category case, the ponds are up to $0.15 \mathrm{~m}$ less deep than the standard CPOM run and, in fact, a similar volume of meltwater is produced in the two cases. Table 3 summarizes the two sensitivity studies considered.

\subsubsection{Alternative Meltwater Redistribution Scheme}

[38] The principle of placing meltwater on the lowest ice first, and only when this is completely covered, placing meltwater on the next lowest ice, and so on, is straightforward and physically based, however the complexity of the real sea ice surface is such that this will not always be possible. Without the ice topography (and other surface characteristics), it is necessary to make assumptions regarding the extent to which meltwater will flow to the lowest ice. In order to address this uncertainty, the sensitivity study presented here takes the available meltwater and distributes it onto height classes in order of increasing height, but with only $50 \%$ of the available area of the height class covered. This means that meltwater is distributed across higher (thicker) ice than would otherwise be the case and also implies that the maximum attainable pond area fraction is $50 \%$.

[39] In Figure 9 we show the seasonal cycle of basinaveraged ice thickness and ice concentration and in Figure 10 we show the seasonal cycle of basin-averaged pond covered area fraction and pond depth with the standard CPOM run of the previous section and an equivalent run with the alternative meltwater redistribution scheme, labeled "apond 0.5."

[40] We see from Figure 9 that the alternative, "apond 0.5 ," meltwater redistribution scheme results in ice which is on average thicker and more concentrated than the standard CPOM scheme. This is because the pond fraction in the "apond 0.5 " scheme is lower at the point in the simulation when melting is greatest, see Figure 10, and thus the effect of the melt ponds on enhancing melt of the ice cover is somewhat reduced. The reason that the pond fraction is lower in the alternative meltwater redistribution scheme in the peak melt period is that only up to $50 \%$ of the available area in any given ice category is covered in meltwater,

Table 3. Minimum and Maximum Values of the Sea Ice Thickness, the Sea Ice Concentration, the Fractional Melt Pond Covered Area, and the Melt Pond Depth for the CPOM, Eight Ice Categories, Alternative "Apond 0.5" Meltwater Redistribution, and Low Permeability Model Runs ${ }^{\mathrm{a}}$

\begin{tabular}{|c|c|c|c|c|c|c|c|c|}
\hline & \multicolumn{2}{|c|}{$\mathrm{Hi}(\mathrm{m})$} & \multicolumn{2}{|c|}{ Aice $(\%)$} & \multicolumn{2}{|c|}{ Apond (\%) } & \multicolumn{2}{|c|}{ Hpond (m) } \\
\hline & Min & Max & Min & Max & Min & Max & Min & $\operatorname{Max}$ \\
\hline СРOM & 0.37 & 1.90 & 0.16 & 0.99 & 0 & 0.44 & 0.03 & 0.47 \\
\hline Eight ice categories & 0.08 & 1.85 & 0.03 & 0.98 & 0 & 0.55 & 0.01 & 0.39 \\
\hline Low permeability & 0.42 & 1.96 & 0.17 & 0.99 & 0 & 0.47 & 0.04 & 0.49 \\
\hline Apond 0.5 & 0.6 & 2.57 & 0.36 & 0.99 & 0 & 0.34 & 0 & 0.49 \\
\hline
\end{tabular}

${ }^{\mathrm{a}} \mathrm{Hi}$, sea ice thickness; Aice, sea ice concentration; apond, fractional melt pond covered area; hpond, melt pond depth. 

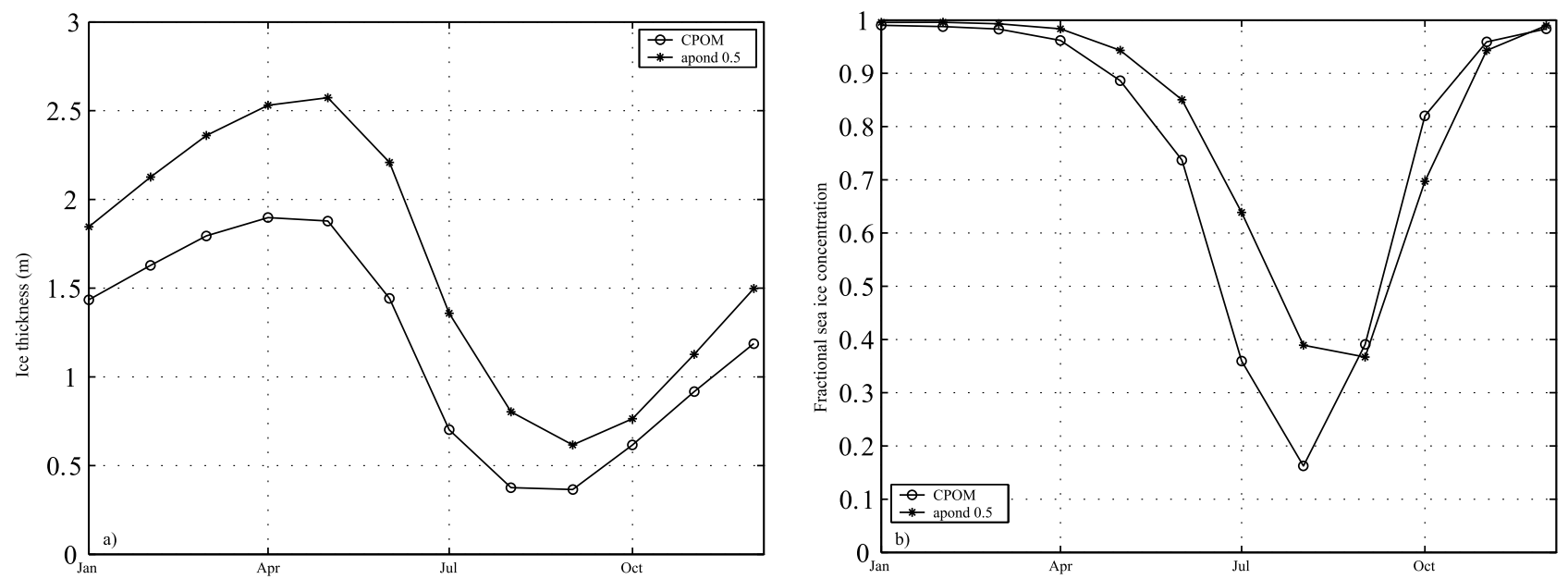

Figure 9. (a) Climatology of the model-domain average of sea ice thickness for the CPOM and the alternative meltwater redistribution model runs. (b) Climatology of the model-domain average of sea ice concentration for the CPOM and alternative meltwater redistribution model runs.

which limits the contribution to total pond fraction from the lower ice height/thickness classes, which are of large area at this time. Similarly, the reason that the pond fraction in the "apond 0.5 " meltwater redistribution scheme is larger than that produced by the standard CPOM redistribution scheme either side of the peak melting period is that, at these times, the average ice thickness distribution has its peak in the intermediate thickness classes. The alternative meltwater redistribution scheme allows meltwater to cover $50 \%$ of these classes of higher ice, after only $50 \%$ of the lowest height/thickness class is completely covered. In the standard scheme, because the lowest ice class must be completely filled, there is insufficient meltwater to cover the higher classes. One should interpret the calculated pond depth, shown in Figure 10, with care; this is the difference in height of meltwater on the thickest ice height class and the height of the lowest ice height class. In fact, the total volume of meltwater produced is lower in the "apond 0.5 " meltwater redistribution scheme. Table 3 summarizes results from this sensitivity study.

\section{Discussion}

[41] The results of the preceding sections demonstrate that the inclusion of melt ponds in a model of sea ice designed for inclusion in a GCM has a significant effect on the predicted ice thickness and ice concentration.

[42] The early onset of the melt season compared to SHEBA observations, Perovich et al. [1999], is due to the early onset of snowmelt in the model. The early onset of snowmelt is not affected by the melt pond routine we have developed. However, once the snow has begun to melt, the melt pond routine is activated and causes meltwater to accumulate. The formation of quite deep ponds at this time is not due to high melt rates (which might be caused by too high fluxes, for example) but due to meltwater accumulating
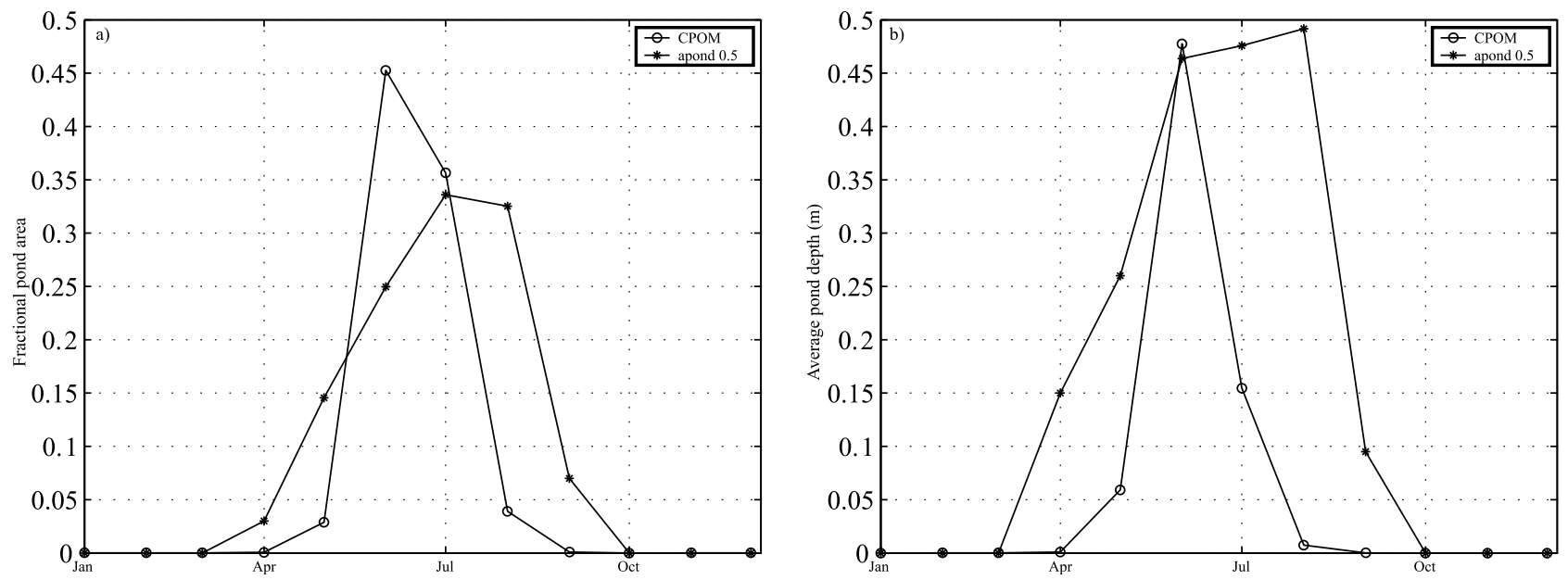

Figure 10. (a) Climatology of the model-domain average of fractional pond area for the CPOM and alternative meltwater redistribution model runs. (b) Climatology of the model-domain average of melt pond depth for the CPOM and the alternative meltwater redistribution model runs. 

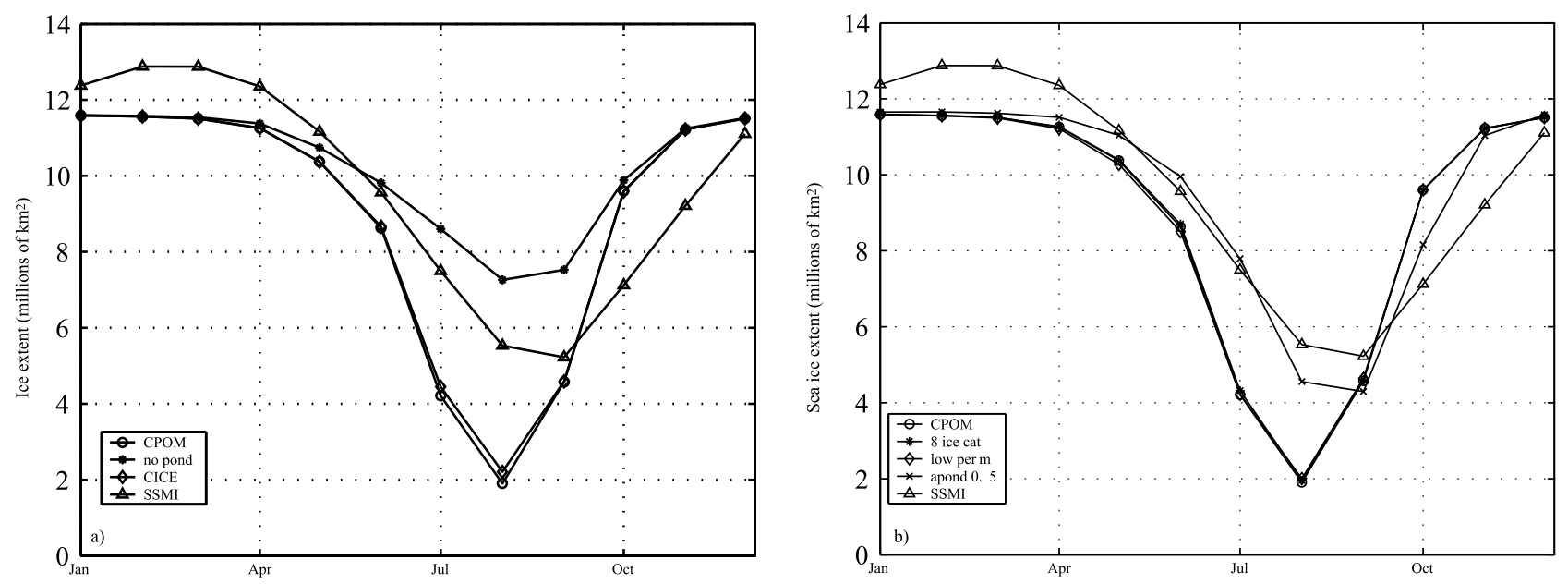

Figure 11. (a) Climatology of the model-domain average of sea ice extent for the CPOM, "no pond," and CICE model runs compared with the sea ice extent calculated using SSMI sea ice concentration data. (b) Climatology of the model-domain average of sea ice extent for the CPOM, eight ice categories, and low permeability model runs compared with the sea ice extent calculated using SSMI sea ice concentration data.

onto the ice of low surface height. Both the CPOM melt pond routine and the semi-empirical melt pond routine act in the same way at this time of year, and have similar pond fractions. That the semi-empirical scheme has a pond maximum in July rather than June is just because it does not account for meltwater drainage and so ponds are above sea level. Ponds above sea level at this time are not observed.

[43] From the simulations of pond fraction, we can conclude that for the period and forcing data considered that the physically based (CPOM) melt pond routine is an improvement over the semi-empirical parameterization in CICE in that it captures the refreezing of melt ponds.

[44] The CPOM melt pond routine distributes meltwater using the surface height (thickness) distribution, which is desirable since it is observed that pond coverage depends upon, in particular, the roughness of the ice cover. This is an improvement over semi-empirical schemes that take no account of the ice thickness distribution (such as the CICE formulation) because as the nature of the ice cover evolves so will the pond coverage. However, the sensitivity study in which the number of ice thickness categories was increased demonstrates that the pond coverage, and hence the mass balance of the ice cover, is sensitive to the number and location of thickness categories. This sensitivity is because of the approximation of a continuous thickness distribution with a small number of discrete thickness categories, e.g., in the work of Flocco and Feltham [2007] eighty thickness categories were used.

[45] Our simulations using either the CPOM or CICE melt pond scheme produce a reasonable climatology of ice thickness, but the ice concentration and extent (shown below) are much too low in summer. This is not surprising since we have deliberately not "tuned" the model against observations, which is the commonly implemented process whereby uncertain parameters describing physical processes such as the ice strength, air-ice drag coefficient, etc are adjusted in order to improve the match between model simulations and observations. In Figure 11 we show model simulations of ice extent against Special Sensor Microwave/Imager (SSMI) estimates of extent calculated using the Bootstrap algorithm [Comiso, 1990]. Sea ice extent is defined here to be the area of sea ice concentration exceeding 15\%. In Figure 11a are shown sea ice extent results for the CICE run with no ponds, the run with the standard CICE melt pond routine, and the run with the CPOM melt pond scheme. The run with no ponds shows a delay in the summer shrinking of the sea ice and too great an extent, with a minimum value of $7 \times 10^{6} \mathrm{~km}^{2}$. The model runs including ponds both produce a sea ice minima about a month earlier than observed (August instead of September) and which is much too small, being about $2 \times$ $10^{6} \mathrm{~km}^{2}$. Figure $11 \mathrm{~b}$ shows that the equivalent simulations of ice extent using the CPOM melt pond scheme but with a higher number of thickness categories or lower permeability differ little from the standard CPOM run. By contrast, the study with the alternative meltwater distribution scheme does a much better job of producing a realistic minimum ice extent. Table 4 summarizes the results.

[46] There may be several factors combining to produce too low an ice extent and ice concentration during the summer months related to, for example, the forcing data set, sea ice rheology, basal melting, etc. Here, since it is relevant to melt ponds, we demonstrate the impact of a change in

Table 4. Summary of the Minimum and Maximum Values of the Sea Ice Extent for the "No Pond," CICE, CPOM, Low Permeability, Alternative "Apond 0.5" Meltwater Redistribution, and Eight Ice Categories Model Runs

\begin{tabular}{llc}
\hline & \multicolumn{2}{c}{ Sea Ice Extent $\left(10^{6} \mathrm{~km}^{2}\right)$} \\
\cline { 2 - 3 } & Min & Max \\
\hline No pond & 7.26 & 11.60 \\
CICE & 2.20 & 11.59 \\
CPOM & 1.90 & 11.59 \\
Low permeability & 1.96 & 11.60 \\
Eight ice categories & 2.00 & 11.59 \\
Apond 0.5 & 4.3 & 11.65 \\
\hline
\end{tabular}



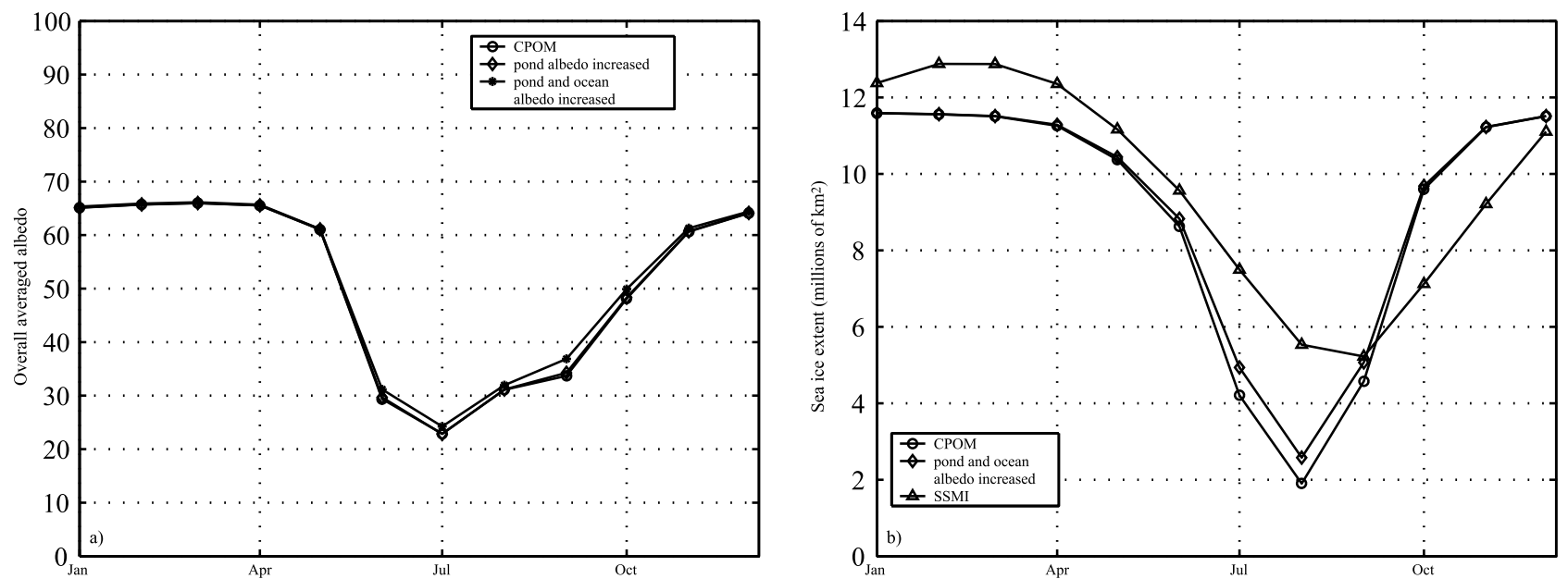

Figure 12. (a) Climatology of the overall model-domain average of albedo for the CPOM run and for the modified CPOM run with increased albedo for the melt ponds and for the ocean. (b) Climatology of the model-domain average of sea ice extent for the CPOM and for the modified CPOM run with increased albedo for the melt ponds and for the ocean compared with the sea ice extent calculated using SSMI sea ice concentration data.

albedo of the melt ponds and ocean. The ocean and melt pond albedo are not part of the melt pond scheme, which only provides melt pond area and depth, but are calculated using the CCSM albedo scheme in CICE. In Figure 12 we show the seasonal cycle of basin-averaged albedo and sea ice extent using the CPOM melt pond scheme for a run in which the pond albedo is arbitrarily increased by $25 \%$ and a run in which, in addition to the increase in pond albedo, the ocean albedo is increased from 0.06 to 0.15 (also shown is the standard CPOM run). We see that the change in albedo values results in a relatively small increase in the sea ice extent of about $0.5 \times 10^{6} \mathrm{~km}^{2}$. The increase in ice thickness and concentration resulting from the increase in albedo is also fairly small, Figure 13. Table 5 summarizes these findings.

[47] Although there are shortcomings in the physically based CPOM melt pond scheme, discussed above, inclusion of this scheme within CICE has allowed the melt ponds to be reproduced within observational bounds. Since the modeled summer ice concentration and extent are too low, even accounting for a viable range of pond and ocean albedos, this suggests that previous simulations with a realistic sea ice extent may have been artificially compensating for the lack of ponds. The relative success of the alternative meltwater redistribution scheme in producing a realistic minimum ice extent suggests that differing choices of redistribution scheme can act as an effective tuning parameter.

\section{Summary and Conclusions}

[48] The failure of the models reported in the IPCC AR4 report to incorporate within their predicted ranges of variability the recently observed, rapid reduction of Arctic sea
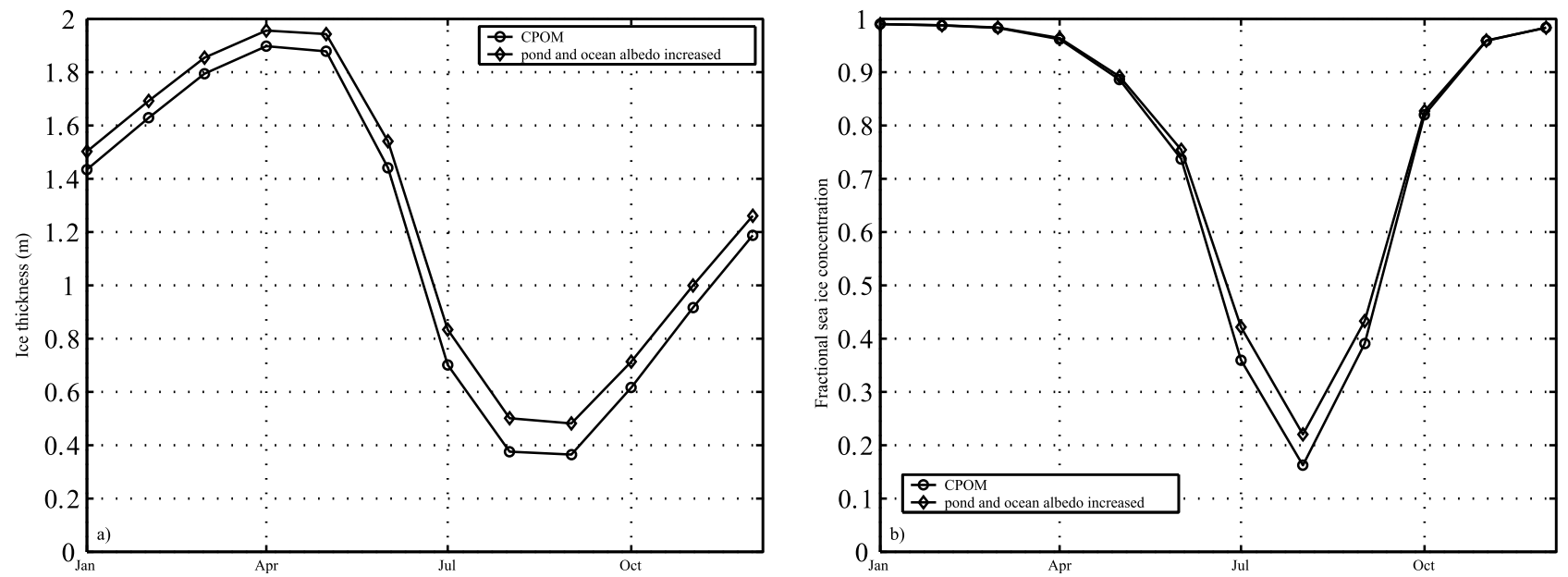

Figure 13. (a) Climatology of the model-domain average of sea ice thickness for the CPOM and for the modified CPOM model run with increased albedo for the melt ponds and for the ocean. (b) Climatology of the model-domain average of sea ice concentration for the CPOM and for the modified CPOM model run with increased albedo for the melt ponds and for the ocean. 
Table 5. Minimum and Maximum Values of the Sea Ice Thickness, the Sea Ice Concentration, the Fractional Melt Pond Covered Area, the Melt Pond Depth and the Ice Extent for the CPOM, Modified CPOM Model Run With Increased Pond Albedo and Then With Increased Pond and Ocean Albedo ${ }^{a}$

\begin{tabular}{|c|c|c|c|c|c|c|c|c|c|c|}
\hline & \multicolumn{2}{|c|}{$\mathrm{Hi}(\mathrm{m})$} & \multicolumn{2}{|c|}{ Aice $(\%)$} & \multicolumn{2}{|c|}{ Apond $(\%)$} & \multicolumn{2}{|c|}{ Hpond (m) } & \multicolumn{2}{|c|}{$\begin{array}{l}\text { Ice Extent } \\
\left(10^{6} \mathrm{~km}^{2}\right)\end{array}$} \\
\hline & Min & Max & Min & Max & Min & Max & Min & Max & Min & Max \\
\hline CPOM & 0.37 & 1.90 & 0.16 & 0.99 & 0 & 0.44 & 0.03 & 0.48 & 1.90 & 11.59 \\
\hline Ponds albedo increased & 0.40 & 1.91 & 0.18 & 0.99 & 0 & 0.45 & 0.01 & 0.49 & 2.12 & 11.59 \\
\hline Ponds and ocean albedo increased & 0.48 & 1.96 & 0.22 & 0.98 & 0 & 0.48 & 0 & 0.53 & 2.60 & 11.59 \\
\hline
\end{tabular}

${ }^{\mathrm{a}} \mathrm{Hi}$, sea ice thickness; Aice, sea ice concentration; apond, fractional melt pond covered area; hpond, melt pond depth.

ice suggests a reanalysis of the physical basis of the sea ice components of these models is warranted. Here, we have focused on incorporating the first physically based representation of melt ponds into the sea ice component of just such a climate model (the Los Alamos CICE model).

[49] Melt ponds form in spring on the Arctic sea ice and by the end of summer they cover almost $50 \%$ of the sea ice surface. Pond-covered ice has a lower albedo than bare ice, and a positive feedback mechanism operates whereby enhanced melt in the presence of ponds results in further production of meltwater and so on. The theoretical basis of a melt pond scheme was presented by Flocco and Feltham [2007]: this scheme distributes meltwater onto the sea ice surface in a manner that takes account of the thickness distribution, vertical drainage of meltwater, and other factors. Here we have incorporated this melt pond scheme into the CICE sea ice model and expanded the theory to include a vertical sea ice permeability that depends upon the state of the ice and a representation of the freezing over of melt ponds.

[50] Our model simulations show that the inclusion of melt ponds in a sea ice model, other factors being held equal, greatly reduces the ice thickness and extent. Our melt pond scheme is compared to a simpler, semi-empirical parameterization included in the standard release of CICE version 4.1. We find that both melt pond schemes have a similar effect on the predictions of thickness, ice concentration, and extent, but that the physically based scheme more realistically deals with the reduction in pond coverage after the melt season has finished, which is because it models the freezing over of the ponds.

[51] Although there are shortcomings in the physically based CPOM melt pond scheme, inclusion of this scheme within CICE has allowed the melt ponds to be reproduced within observational bounds. Since the modeled summer ice concentration and extent are too low, even accounting for a viable range of pond and ocean albedos, this suggests that previous simulations with a realistic sea ice extent may have been artificially compensating for the lack of ponds. The relative success of the alternative meltwater redistribution scheme in producing a realistic minimum ice extent suggests that differing choices of redistribution scheme can act as an effective tuning parameter. This implies that an in depth sensitivity study of a sea ice model including melt ponds is required to calibrate sea ice models with ponds.

[52] The distribution of meltwater in our physically based melt pond routine is determined using the thickness distribution so that, for example, the presence of a large area of thin ice will result in shallow ponds of large area. This is an improvement over semi-empirical schemes that take no account of the ice thickness distribution (such as the CICE formulation) because as the nature of the ice cover evolves so will the pond coverage, e.g., in recent years the fraction of relatively smooth first year ice has increased in the Arctic [Cavalieri et al., 2003]. Our sensitivity study in which the number of ice thickness categories was increased demonstrates that the pond coverage, and hence the mass balance of the ice cover, is sensitive to the number and location of thickness categories. This sensitivity is because of the approximation of a continuous thickness distribution with a small number of discrete thickness categories, e.g., in the work of Flocco and Feltham [2007] eighty thickness categories were used. Rather than dramatically increase the number of thickness categories, we recommend that a more practical option for the sea ice components of GCMs incorporating our melt pond scheme is to implement a modest increase in the number of thickness categories but to focus the thickness categories toward thinner ice, which is more likely to be covered in melt ponds. The sensitivity study in which the CPOM meltwater redistribution scheme was altered to allow only $50 \%$ of each ice height class to be covered in meltwater was able to produce an ice extent closer to observations, suggesting that investigation of the appropriate meltwater redistribution scheme for GCM-style sea ice models is warranted.

[53] Acknowledgments. We acknowledge two anonymous reviewers, whose insightful comments have helped us improve the manuscript. D.L.F. acknowledges financial support made available through the award of a research prize by the Leverhulme Trust. We acknowledge financial support made possible under the Arctic Synoptic Basin-wide Oceanography consortium grant, awarded by the National Environmental Research Council of UK.

\section{References}

Assur, A. (1958), Composition of sea ice and its tensile strength, in Arctic Sea Ice: Conference Held at Easton, Maryland, February 24-27, 1958, vol. 598, pp. 106-138, Natl. Res. Counc., Washington, D. C.

Barber, D. G., and J. Yackel (1999), The physical, radiative and microwave scattering characteristics of melt ponds on Arctic landfast sea ice, Int. $J$. Remote Sens., 20(10), 2069-2090, doi:10.1080/014311699212353.

Bitz, C., and W. Lipscomb (1999), An energy-conserving thermodynamic model of sea ice, J. Geophys. Res., 104, 15,669-15,677, doi:10.1029/ 1999JC900100.

Carslaw, H. S., and J. C. Jaeger (1997), Conduction of Heat in Solids, 2nd ed., Clarendon, Oxford, U. K.

Cavalieri, D. J., C. L Parkinson, and K. Y. Vinnikov (2003), 30-Year satellite record reveals contrasting Arctic and Antarctic decadal sea ice variability, Geophys. Res. Lett., 30(18), 1970, doi:10.1029/2003GL018031.

Comiso, J. (1990), DMSP SSM/I daily and monthly polar gridded bootstrap sea ice concentrations, http://nsidc.org/data/docs/daac/bootstrap/index. html, edited by J. Maslanik and J. Stroeve, Natl. Snow and Ice Data Cent., Boulder, Colo. 
Derksen, C., J. Piwowar, and E. LeDrew (1997), Sea-ice melt-pond fraction as determined from low level aerial photographs, Arct. Alp. Res., 29(3), 345-351, doi:10.2307/1552150.

Ebert, E. E., and J. A. Curry (1993), An intermediate one dimensional thermodynamic sea ice model for investigating ice-atmosphere interactions, J. Geophys. Res., 98, 10,085-10,109, doi:10.1029/93JC00656.

Eicken, H., H. R. Krouse, D. Kadko, and D. K. Perovich (2002), Tracer studies of pathways and rates of melt water transport through Arctic summer sea ice, J. Geophys. Res., 107(C10), 8046, doi:10.1029/ 2000JC000583.

Eicken, H., T. C. Grenfell, D. K. Perovich, J. A. Richter-Menge, and K. Frey (2004), Hydraulic controls of summer Arctic pack ice albedo, J. Geophys. Res., 109, C08007, doi:10.1029/2003JC001989.

Feltham, D. L., N. Untersteiner, J. S. Wettlaufer, and G. M. Worster (2006), Sea ice is a mushy layer, Geophys. Res. Lett., 33, L14501, doi:10.1029/ 2006GL026290.

Fetterer, F., and N. Untersteiner (1998a), Observations of melt ponds on Arctic sea ice, J. Geophys. Res., 103, 24,821-24,835, doi:10.1029/ 98JC02034.

Fetterer, F., and N. Untersteiner (1998b), Melt pond coverage statistics from classified satellite data, in IGARSS '98 Sensing and Managing the Environment: 1998 IEEE International Geoscience and Remote Sensing Symposium Proceedings, edited by T. I. Stein, pp. 1954-1956, Inst of Elect. and Electr. Eng., Piscataway, N. J.

Flato, G., and W. Hibler III (1995), Ridging and strength in modeling the thickness distribution of Arctic sea ice, J. Geophys. Res., 100 $18,611-18,626$

Flocco, D., and D. L. Feltham (2007), A continuum model of melt pond evolution on Arctic sea ice, J. Geophys. Res., 112, C08016, doi:10.1029/ 2006JC003836.

Golden, K. M., H. Eicken, A. L. Heaton, J. Miner, D. J. Pringle, and J. Zhu (2007), Thermal evolution of permeability and microstructure in sea ice, Geophys. Res. Lett., 34, L16501, doi:10.1029/2007GL030447.

Grenfell, T. C., and G. A. Maykut (1977), The optical properties of ice and snow in the Arctic basin, J. Glaciol., 18(80), 445-463.

Hibler, W. D., III (1979), A dynamic thermodynamic sea ice model, J. Phys. Oceanogr., 9, 815-846, doi:10.1175/1520-0485(1979) 009<0815:ADTSIM>2.0.CO;2.

Hunke, E. C., and J. K. Dukowicz (1997), An elastic-viscous-plastic model for sea ice dynamics, J. Phys. Oceanogr., 27, 1849-1868, doi:10.1175/ 1520-0485(1997)027<1849:AEVPMF>2.0.CO;2.

Laxon, S., N. Peacock, and D. Smith (2003), High interannual variability of sea-ice thickness in the Arctic region, Nature, 425, 947-950.

Light, B., T. C. Grenfell, and D. K. Perovich (2008), Transmission and absorption of solar radiation by Arctic sea ice during the melt season, J. Geophys. Res., 113, C03023, doi:10.1029/2006JC003977.

Linden, P. F. (2000), Convection in the environment, in Perspectives in Fluid Dynamics: A Collective Introduction to Current Research, edited by G. K. Batchelor et al., pp. 289-345, Cambridge Univ. Press, New York.

Lipscomb, W. H., E. C. Hunke, W. Maslowski, and J. Jakacki (2007), Ridging, strength, and stability in high-resolution sea ice models, $J$. Geophys. Res., 112, C03S91, doi:10.1029/2005JC003355.

Lüthje, M., D. L. Feltham, P. D. Taylor, and M. G. Worster (2006), Modeling the summertime evolution of sea-ice melt ponds, J. Geophys. Res., 111, C02001, doi:10.1029/2004JC002818.

Madec, G. (2008), NEMO ocean engine, Notes du Pole de Modélisation, 27, Institut Pierre-Simon Laplace, Paris.
Maykut, G. A., and N. Untersteiner (1971), Some results from a timedependent thermodynamic model of sea ice, J. Geophys. Res., 76 1550-1575, doi:10.1029/JC076i006p01550.

Miller, P., S. W. Laxon, D. L. Feltham, and D. Cresswell (2006), Optimization of a sea ice model using observations of Arctic Sea ice thickness, extent, and velocity, J. Clim., 19, 1089-1108, doi:10.1175/JCLI3648.1.

Perovich, D. K. (1996), The optical properties of sea ice, Monogr., 96-1, 25 pp., Cold Reg. Res. and Eng. Lab., Hanover, N. H.

Perovich, D. K. (2005), On the aggregate-scale partitioning of solar radiation in Arctic sea ice during the SHEBA field experiment, J. Geophys. Res., 110, C03002, doi:10.1029/2004JC002512.

Perovich, D. K., and W. B. Tucker III (1997), Arctic sea-ice conditions and the distribution of solar radiation during summer, Ann. Glaciol. $25,445-450$.

Perovich, D. K., T. C. Grenfell, B. Light, J. A. Richter-Menge, M. Sturm, W. B. Tucker III, H. Eicken, G. A. Maykut, and B. Elder (1999), SHEBA: Snow and Ice Studies [CD-ROM], version 1.0, Cold Reg. Res. and Eng. Lab., Hanover, N. H.

Perovich, D. K., W. B. Tucker III, and K. A. Ligett (2002), Aerial observations of the evolution of ice surface conditions during summer, J. Geophys. Res., 107(C10), 8048, doi:10.1029/2000JC000449.

Perovich, D. K., T. C. Grenfell, J. A. Richter-Menge, B. Light, W. B. Tucker III, and H. Eicken (2003), Thin and thinner: Ice mass balance measurements during SHEBA, J. Geophys. Res., 108(C3), 8050, doi:10.1029/2001JC001079.

Rothrock, D. A. (1975), The energetics of the plastic deformation of pack ice by ridging, J. Geophys. Res., 80, 4514-4519.

Rothrock, D. A., Y. Yu, and G. A. Maykut (1999), Thinning of the arctic sea-ice cover, Geophys. Res. Lett., 26, 3469-3472, doi:10.1029/ 1999GL010863.

Solomon, S., et al. (2007), Technical summary, in Climate Change (2007): The Physical Science Basis: Contribution of Working Group I to the Fourth Assessment Report of the Intergovernmental Panel on Climate Change, edited by S. Solomon et al., pp. 19-91, Cambridge Univ. Press, Cambridge, U. K.

Steele, M., R. Morley, and W. Ermold (2001), PHC: A global ocean hydrography with a high quality Arctic Ocean, J. Clim., 14, 20792087, doi:10.1175/1520-0442(2001)014<2079:PAGOHW>2.0.CO;2.

Stroeve, J., M. M. Holland, W. Meier, T. Scambos, and M. Serreze (2007), Arctic sea ice decline: Faster than forecast, Geophys. Res. Lett., 34, L09501, doi:10.1029/2007GL029703.

Taylor, P. D., and D. L. Feltham (2004), A model of melt pond evolution on sea ice, J. Geophys. Res., 109, C12007, doi:10.1029/2004JC002361.

Thorndike, A. S., D. A. Rothrock, G. A. Maykut, and R. Colony (1975), The thickness distribution of sea ice, J. Geophys. Res., 80, 4501-4513, doi:10.1029/JC080i033p04501.

Tschudi, M. A., J. A. Curry, and J. A. Maslanik (2001), Airborne observations of summertime surface features and their effect on surface albedo during FIRE/SHEBA, J. Geophys. Res., 106, 15,335-15,344, doi:10.1029/2000JD900275.

Zhang, J., D. A. Rothrock, and M. Steele (1998), Warming of the Arctic Ocean by a strengthened Atlantic inflow: Model results, Geophys. Res. Lett., 25, 1745-1748, doi:10.1029/98GL01299.

D. L. Feltham, D. Flocco, and A. K. Turner, Centre for Polar Observation and Modelling, Department of Earth Sciences, University College London, Gower St., London, WC1E 6BT, UK. (d.flocco@cpom.ucl.ac.uk) 